\title{
Epidural Block
}

National Cancer Institute

\section{Source}

National Cancer Institute. Epidural Block. NCI Thesaurus. Code C15642.

An anesthetic procedure that involves administering pharmaceutical agents into the epidural space of the spinal canal. Frequently administered agents include local anesthetics and analgesics. 